\title{
AN INVESTIGATION INTO CONTRACT CHEATING IN TERTIARY EDUCATION, AND HOW TO COMBAT THE PROBLEM IN A UNITED ARAB EMIRATES CONTEXT
}

\author{
Andy Pacino ${ }^{1}$ \\ ${ }^{1}$ M. Ed, MA (TESOL). ELT Central, UK
}

ARTICLE INFO

Recieved: 06 September 2021

Revised: 16 October 2021

Accepted: 18 October 2021

\section{Keywords:}

Contract Cheating, Tertiary Education, Fraud Triangle

Theory

Corresponding Author:

Andy Pacino

Email: andypac@gmail.com Copyright (C) 2021, Middle Eastern Journal of Research in Education and Social Sciences.

This work is licensed under the Creative Commons Attribution International License (CC BY 4.0). $\mathrm{http} / / /$ creativecommons.org/licenses/ by/4.0/
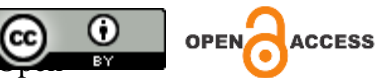

\section{ABSTRACT}

This review article investigated the pervasive problem that contract cheating presents in higher education in the United Arab Emirates (UAE), and aimed to discover whether a solution could be found to combat the growing use of essay mills among students in the region. This literature review aimed to answer the following research questions; why do students use essay mills? Is current university student academic support adequate to facilitate branch campus learning at a level equivalent to a home campus? What methods can international branch campuses in the UAE employ to discourage the use of essay mills? What type and levels of services can universities provide in the future that better support students and stop them from becoming potential essay mill users? The point of the research was to find a means by which students can be dissuaded from using contract cheating sites by becoming so well-supported, and so aware of the threat that contract cheating poses to the value of their degree, that essay mills become a much less attractive option. The study began with a look into the possible circumstances that lead a student to cheat, which includes exploring the fraud triangle theory, the peer behaviour theory, the planned behaviour theory, and the subsequent methodology used. The study found a variety of reasons students cheat, citing laziness, a lack of ability or adequate depth of academic vocabulary in a second language learner, peer pressure, that it is so easy and convenient to use such sites, and the fact that there is a promise of plagiarism free work with a click of a mouse and simple financial transaction (Clarke \& Lancaster, 2013). Furthermore, online contract cheating presents a significant challenge for higher education institutes to keep a check on standards and quality assurance. Many teachers are either unaware of or simply afraid to follow up on instances of contract cheating for fear of recriminations in the form of poor feedback or possible student dropout rates.

\section{INTRODUCTION}

This review investigates the growing use of contract cheating - also known as essay mills - and the catastrophic effect they could have on tertiary education in the United Arab Emirates (UAE), as well as other regions, and what could be done to prevent the growth of the industry, or to dissuade students from ever having to use them in the first place. The report will; (1.1) provide the background and (1.2) positionality of the researcher, and (1.3) the theoretical framework used in the review. Following that, it will provide the methodology (2) used, then 
present a discussion (3) and analysis, before finally wrapping up with (4) findings and suggestions for future research.

\section{Background And Context}

Academic integrity is at the forefront of an educational institute's assurance of the quality of degree standards (the University of Toronto, n.d.). Along with the spread of global Internet connectivity, there has been a huge rise in the number of essay mills and contract cheating sites advertised worldwide (Clarke \& Lancaster, 2013). The problem has become worse since such services have become so much cheaper due to the online abundance (Husbands, 2019). This brings the authenticity and value of degree certificates and qualifications under attack. As there are 37 branch campuses in the UAE and, therefore, more likely to have students who speak English as a second language, those who do not have a good grasp of English may be more inclined to use essay mills. There are more than 80 universities and colleges in the region; therefore, it is vital these institutions address (and attempt to find a resolution) to the issue. Through investigating current and recent literature, this review explores and attempts to address issues such as; why do students use essay mills? Are universities doing enough to provide students with adequate academic support? What methods can universities employ to discourage the use of essay mills? What services can universities provide in the future that better support potential essay mill users?

One of the most concerning challenges higher education faces in modern times is that of contract cheating, or the essay mill (Clarke \& Lancaster, 2006). It could easily be argued that the rise of such service provisions could even undermine the whole structure of university degrees. The number of students enrolled in higher education in the UAE has grown from just under 10,000 in the year 2000 to an estimated 1.4 million in 2020 (UAE Higher Education, n.d.). In around 2008, blended learning was introduced in many universities (AlKaabi et al., 2016), which brought with it the problem of keeping stock of whether or not the work being submitted is genuinely student-authored. Newton's study (2018) revealed contract cheating is on the increase, and unless moves are made to combat the practice, there is no knowing where it could end. Essay mills have been plying their trade for many years, however, with the rise in use of the Internet, the industry has boomed (Lee, 2019), with some companies even going so far as advertising their services on university campus notice boards as well as via the systematic infiltration of many social media applications students use, such as TikTok, Instagram, Facebook, and Twitter, to entice fresher students into their clutches (Turner et al., 2018). The problem has become so pressing that it has been discussed at the highest level in the UK, with Education Minister, Joe Johnson, calling for an in-depth investigation and more robust methods to combat it (Elmes, 2017; McCabe et al., 2001). It is true to say the services are not yet illegal everywhere, though the impact they could have, could certainly threaten the validity and/or credibility of the whole higher education system (Elmes, 2017).

Current studies focus on a wide variety of essay mill users though few address the possibility of discouraging through more robust support for the student. The recently released Tertiary Education Quality Standards and Assurance (TEQSA) "toolkit" (TEQSA, 2020), which is aimed directly at combatting the essay mill industry, mentions the term 'support' 32 times in its brochure. Astonishingly, the report makes only a single mention of actually supporting the 
students. The majority of the paper is aimed at supporting teaching staff and protecting academic integrity. In the UAE, there is little outside basic teacher guidance and student support officers who may have a meagre amount of time to give to individuals to usher them away from the cusp of temptation. An added factor is that universities need bums on seats in order to turn a profit, which could mean institutions fail to thoroughly investigate or punish cheating students, though without an admission of cheating wrongdoing is difficult to prove (Crossman, 2019). Indeed, QAA found more than 17,000 academic integrity issues during the 2013 to 2016 period, and admit this could be only the tip of the iceberg as many instances go undiscovered (Department of Education, 2019).

Prior studies have looked into the reasons there has been such a growth in the essay mill industry and the rise in the number of students who choose to cheat rather than complete the course on merit (Husbands, 2019), which points to a lack of preventative measures in place from the very institutions becoming infested by adverts from essay mill companies. While this research initially investigated the growing use of contract cheating in tertiary education (focusing on second language speakers studying in tertiary education in the UAE), it will also explore the reasons these students find themselves in a situation where they feel they need to cheat. As previous research has found a chasm in the support offered (Quality Assurance Agency, 2017), it will attempt to discover ways in which universities in the region can provide students with adequate support to discourage them from using these services.

\section{Positionality}

I have been the Teaching and Learning Coordinator and Student Learning Adviser for several university education providers in a satellite (branch) campus operation in the UAE from April 2017 to March 2020. My duties involved providing students with all aspects of academic writing assistance and advising them should they be found guilty of committing academic integrity issues in such cases. After an initial meeting with the Dean, offending parties were sent to me so that I could point out and help address the errors of their ways and to offer advice on avoiding further issues. Every one of the students I spoke to in this regard had been guilty of committing academic dishonesty, and every one of them had plagiarized. The majority said it had been accidental; however, most of the work was far too close to the original material for that to be the case. Some said they did not realize they weren't allowed to copy and paste, while some stated they knew but were late delivering assignments and too close to the deadline to submit their own work. Cases were relatively straightforward using similarity-checking software, Turnitin, and Urkund, discovered the majority of them. When students were caught, there was little denial. When the offender was shown where their work was too close to the original to be a coincidence, most of them admitted their guilt, and subsequently completed mandatory training on how to avoid breaching the university's code of academic integrity. For the final two terms of 2019, as we shall see, this changed.

As a teacher, I was well aware of students' capabilities and levels of English, and it was relatively simple for me to recognize work that was original and that which was not. During the final two terms of 2019, I noticed a change in a number of students' work. The quality of argument, the vocabulary and the style were markedly different from the work they had previously submitted. Curiously, their work passed the similarity checks, which I found a cause 
for concern, and I raised the issue with the Dean. Proving the work was not original, however, was another matter: unless the student admitted to it, there was little that could be done to prove they had cheated.

The reason I wish to explore this area is that I believe there is a gap in the amount of student support that needs addressing, and I suspect that cheating is far more widespread than we realise. This could have a number of serious knock-on effects, the main issue being the concern for the educational and vocational value of the degrees offered in the region. Secondly, I genuinely feel there needs to be more language and academic support than there is currently offered. Finally, I would like to conduct the proposed research to complete the study and bring about a change in the way support is provided to non-native and second-language English speakers.

The vast majority of UAE undergraduate and postgraduate students embarking on an English language medium degree are second language speakers (Zayed, 2015). Many do not have a solid enough foundation in the language to sufficiently explain their points or arguments in an academic manner (Barnard \& McLellan, 2013). Students who face failure are more likely to be tempted into turning to the services of an essay mill. I have also noticed a growing problem of linguistically substandard undergraduate student admissions, and having an understanding of the financial implications, this is possibly because universities need paying customers to survive. While many students may qualify for admission on paper, too many do not meet the required standard to complete their degree successfully (Ali, 2019). These students could end up paying a ghostwriter to complete part or the whole of their degree assignments (Sawir, 2005), and in doing so devalue both the university reputations and its alumni's qualifications (Eisenberg, 2004). This study is important to me and close to my heart as an educator as it means I will gain a better understanding of the areas where students have problems, and this research will help me address the issues, at least for the students I advise. The UAE is a prime area for a focus of study as there many international branch and satellite campuses and by investigating where the biggest problems lie the findings will hopefully make better students of those attending universities in the region. The following literature review will offer an analysis of recent research on plagiarism focusing on essay mills and the information herein is relevant to the proposed research question.

\section{THEORETICAL FRAMEWORK}

Cressy's social cognitive fraud triangle theory (1973), along with perceived peer behaviour (McCabe et al., 2001), and planned behaviour (Uzun \& Kilis, 2020; Azjen \& Madden, 1986) theories have been used in this review. The fraud triangle covers the three aspects that Cressy (1973) states lead a person to commit fraud. These aspects are; the perceived unshareable financial (academic) need, the perceived opportunity and the rationalisation of the act (Cressy, 1973). Along with the rise of digital technology came the opportunity for students to copy and paste swathes of text from websites to pass off as their own. Although similarity checking software has proved effective combatting such, the growth in the essay mill industry has seen work passing similarity checking software scrutiny due to the original nature of the work, even though it was not the work of the student (Ma et al., 2008). 
The aspect of opportunity focuses on the plethora of essay mills advertising on social media through sites such as Facebook, Instagram, and even professional social media sites such as Linkedin. The level of advertising on these sites is quite staggering, and it is difficult for students to miss or ignore them. A recent Internet search of the term 'essay mill' returned 37.9 million hits (the count has grown from 31.4 million over a three month period and continues to rise). Students are continually bombarded with advertisements and friend requests from essay mill sites and contract cheats offering cheap essay work, albeit with a caveat that it must not be submitted as their original work. Teachers, too, are approached via these sites with promises of kick-backs for recommendations to their service. With opportunities of this nature and with such a volume to choose from, it is easy to see how a struggling student could fall prey to this practice. The digital nativeness of the modern student means they prefer using an Internet browser rather than the library (Davies \& Howard, 2016), and this, along with the increasing use of social media advertising, sees many students succumbing to temptation.

As many of the students in tertiary education in the UAE are second language speakers, a large proportion of them do not have the language capacity to convey their written assignments as clearly as their native-speaking contemporaries might. Indeed, Sawir's (2005) study revealed English language teaching standards in East and Southeast Asia do not meet the levels required for English medium degrees. As branch campus assignments and exams are often moderated by native English speaking based institutions, second language students can find themselves disadvantaged, which is how students rationalise the purchase of third party-written assignments. Peer behaviour is another factor, and as McCabe et al. (2001) discovered; when students see the amount of cheating their friends get up to, it has a knock on effect on others who will follow suit and cheat. That said, there is evidence that there is a certain level of an honour code that prevents the majority of students from cheating (McCabe et al., 2001), however, with such an array of so many easily accessible sources, the temptation to use essay mills could prove too difficult to resist for some of those struggling due to language issues (McCabe et al., 2001). That said: the whole point of a university degree is that one is able to demonstrate a level of learning adequate to pass the course (Husbands, 2019). Reiterating, Cressy (1973) confirms the three distinct factors required to complete the fraud triangle are the need, which could lie in the laziness and/or the inability to complete a project, the opportunity that presents itself in the form of essay mill advertising, and finally, the fraud: the purchase of the assignment. Research also revealed a direct link between a person's belief that they will not be caught and the likelihood of committing a fraud (Coren, 2012; Azjen \& Madden, 1986). Clearly, there is quite some problem in this area that requires looking into. As the subject warrants further investigation, this study explored reasons and motivation behind cheating, using essay mills in particular and how students may be given correct and proper support to dissuade them from doing so.

\section{METHODOLOGY AND PROCEDURES}

The main database for this proposal's sources was Murdoch University's library, which provided extensive source material into plagiarism in tertiary education. Research also revealed there was a huge upsurge in the use of essay mills, which presents a major threat to the validity of higher education qualifications and shows there is a weakness in the way assignments, certainly those offered via either distance (online) or through a blended learning model, are 
assessed and graded. In order to fully investigate the issue, Elsevier, ResearchGate and Proquest Central, as well as Google Scholar and general Google searches were used.

In all, more than 120 research projects were sourced, and of those 69 were used. Excluded was any research directly related to medical, mathematics, coding, or technology related cheating and searches focused only on those related to the arts and humanities, as these are the areas that affect this area of study primarily; however, some of the figures did relate to one or more of these disciplines. Secondary search terms included 'support for second language speakers in international branch campuses' and 'support for non-English speakers in tertiary education'. These searches revealed only one study, which was conducted in Hong Kong (Chapman \& Lupton) and carried out in 2004. The sources used in this research are original. There was no trace of a journal relating to this field of study in the UAE found, which highlighted the need for such. Analyzing the research meant drawing common or similar themes from which to analyses factors that could tempt students to use essay mills. The sources used in this research are original.

Common themes were compared and contrasted to gain a fuller understanding of a struggling or cheating student's perspective. Research revealed there were instances of teachers having students prepare hand-written examples of short essays early on in their units to use as guides of ability and style to compare with assignments presented in future that may be ghostwritten (Singh \& Remeney, 2015), although this was rarely followed up in subsequent units or with sophomore or final year students, which is from where most of the problems seemed to stem (Smith et al., 2004).

Search terms included 'plagiarism', social media advertising essay mills', 'essay mills', 'contract cheating', 'why students plagiarize', 'why students use essay mills', 'what drives students to cheat', 'methods of plagiarizing', 'social media in tertiary education', dishonesty in tertiary education', 'essay mill use in the UAE', 'contract cheating in the UAE', 'second language plagiarism', 'social media in English' and 'international students use of essay mills'. Criteria for viable research included peer-reviewed journals where abstracts closely related and aligned to the nature of this study. Also included were articles from higher education supplements and reputed news organizations and their websites. Areas of previous research focused on the terminology and descriptions of what constitutes plagiarism, however, as there has already been so much written in that area, this review aimed to investigate specifically contract cheating and essay mills. Information was gathered, analyzed, compared and contrasted in order to find a broad view of the literature and where future recommendations could be made.

\section{RESULTS AND DISCUSSION}

The need for students to provide original and appropriate work for their degree course is paramount for their knowledge of the subject, the validity of their degree, and the university's reputation for delivering quality education and subsequent certification. In order of the questions, this area of discussion will outline, investigate and address the various problems the surge in essay mill sites and services bring to academic integrity and the resulting (and lasting) problems such could leave (3.1). This will be followed by investigating the challenges second language speakers face (3.2.1), the perception of what constitutes cheating (3.2.2), the reasons students feel the need to cheat (3.2.3), and peer behaviour: how students reconcile themselves 
with cheating (3.2.4). The discussion wraps up with a look into possible solutions to discourage or dissuade students from cheating, specifically by use of essay mills (3.3).

\section{The Rise in Contract Cheating in Higher Education and its Effect}

Figures show that contract cheating in higher education is on the rise (McCabe, 2004). As more universities turn to online education, under-pressure students turning to essay mills to complete their assignments could exacerbate the problem. Indeed, Mellar et al. (2018) provide evidence that ubiquitous technology has compounded the issue, while Crane (n.d.), reports cheating has become an acceptable part of university life in the United States (US). Considering this, and with blended learning models in tertiary education on the increase (Kelly, 2017), teachers have less opportunity to recognise individual levels of capability or standards of work expected from their students as they might in a more personal, student-facing classroom (Mellar et al., 2018). Ensuring the quality of academic integrity is vital to a university's standing and integral to its reputation and the validity of its degree courses (Miller et al., 2011). That essay mills could undermine this is of significant concern; so much so that in 2017, the UK's Universities Minister for Education, Joe Johnson, requested the UK based educational body, Quality Assurance Agency (QAA), to make plans to combat the problem (Elmes, 2017). If the problem is to be addressed with efficiency, then the focus could prove more effective with greater support for the student rather than focussing on locking the door once the horse has already bolted. Studies have revealed a constant and continual rise in academic integrity issues over the past 30 years (McCabe, 2004). This has been exacerbated by the introduction of essay mills' online availability.

\section{Academic Writing Challenges of Second Language English Speaking Students}

With visa restrictions among the world's most stringent, the goal of a university education for ex-pat students in the UAE is both intrinsic (aids vocationally) and extrinsic (residence permits), where the credential is the aim rather than the academic achievement (Wolverton, 2016). With most essay mills offering 'plagiarism-free' returns, many students who face language issues, certainly those have made their way into university by using unscrupulous methods, would feel little guilt over further use of corrupt essay mills (Kaktinš̌, 2018). Many second language students do not have the linguistic capacity to fully grasp or identify with a subject and thereby suffer under the challenge (Lillis, 2001). An added hurdle is the genuine fear of being thought of as stupid should a student ask the teacher too many questions (Weimer, 2009).

Branch campuses should provide students with their education at the same standards and aspects as the mother campus delivers. A home campus appointed Dean would usually oversee academic delivery and ensure that standards are maintained. In the UAE, the majority of students attending university are non-native and second-language speakers of English as there is such a high volume of different nationalities who live here. Although Gassin's study stemmed from research conducted in 1982, it still holds many valid points for the non-native speaking student. Some will have had extensive exposure to the language; however, fossilised mistakes and the common use of directly translated first language expressions mean they do not possess native writing or spoken ability or pronunciation (Gassin, 1982). Other students from the Middle East and North African countries will have similar problems, perhaps exacerbated due 
to English being a foreign rather than second language (Neumann, 1985). Other obstacles are the nuances and quirks of English - idioms and phrasal verbs for example - can be problematic for non-native English speakers. These students could easily be left some way behind other students, with a smaller number of them attaining grades they could achieve if the degree were delivered in their native tongue; while they fully understand the subject matter they may not be able to explain themselves in a fluent manner (Neumann, 1985).

\section{What Students Believe Constitutes Cheating}

The 1979 Carnegie Council Report stated that while students understood what cheating was, they believed some of it was acceptable if they wanted to achieve desired grades. The McCabe et al. (2001) study discovered similar findings, and that $75 \%$ of the students surveyed felt cheating was not only acceptable but also nothing out of the ordinary. This mindset is not unusual and continues in modern studies (Clarke \& Lancaster, 2006). Even though universities go to great lengths to educate their students to veer away from cheating and brief them on the consequences of being caught doing so could be quite severe, the practice continues.

There are forms of cheating that students either do not recognise as, or believe are of little importance (Krou, 2015); discussing exam questions with former examinees, using study banks, and assisting fellow students with their assignments to gain a better grade (passive dishonesty) are all seen as acceptable (Jurdi et al., 2012; Anitsal et al., 2009). Active dishonesty includes the use of essay mills, direct copying from a friend or copy-pasting from a website, and $20 \%$ of students were reported to believe that using direct quotes from a book without citation is legitimate (Carpenter et al., 2006). Most concerning, however, was that students believed if most of their peers engaged in the practice, there was nothing wrong with everyone else following their example (McCabe et al., 2006).

\section{The Motivation to Cheat}

While there is a general code of honour among the majority of students (Bennet, 2005), Bamford and Sergio (2005) support the theory that the majority of cheating is by mistake rather than design. However, Bennet (2005) goes against this, stating that it is due to the introduction of more written-heavy assignments and students being overloaded with work that pressures them into cheating. A number of students in Comas-Forgas and Sureda-Negre's study (2010) stated that; assignment-heavy terms, a belief they will not be detected, that their teacher is techdumb and that they thought they were able to get away with it were reasons they felt they either needed to or were able to cheat. While there is no doubt the Internet makes cheating far easier than it has ever been previously, it does not follow that it incites or encourages honest students to change their habits (Furedi, 2003). Furthermore, it is more the failure to check or follow up on academic integrity procedure that has encouraged cheating (Coren, 2012; Davis et al., 1992). Peer pressure is one of the main motivations behind cheating, and should one classmate see another cheating, he would be even more inclined to follow suit (McCabe, 1999 as cited by Sarita, 2015). Youngsters are more likely to copy behaviour than their elder counterparts due to peer behaviour (McCabe et al., 2001), though even at the cusp of adulthood peer pressure is one of the most difficult to resist influences (Simmonds, 2018), which is again in line with the 
McCabe et al. study (2001). Parental pressure, too, is so influential that it has been the motivation for many students to cheat as they feel expectations and certainly the financial pressure some parents put themselves under to put their offspring through education has an effect on their children (Taylor et al., 2002). The method of so-called 'Tiger Parenting' (the child's achievement is never good enough) in some Asian cultures also adds pressure to their child's academic performance (Kim, 2020). However, the biggest motivating factor driving students to cheat was the fear of failing an assignment (Bennet, 2005). This proved to be an even greater 'incentive' to engage in dishonesty than ethics, the fear of getting caught and the subsequent punishment was to deter them.

\section{How students reconcile themselves with cheating}

Technology such as Apple's SIRI ${ }^{\mathrm{TM}}$ and Amazon's Alexa ${ }^{\mathrm{TM}}$ have made gaining access to knowledge easier than it has ever been, and students asking invisible friends for answers they do not know themselves have little guilt in using technology's answers when they have few of their own (Simmonds, 2018). While the vast majority of cheating students are under no illusions that they are going against an institution's moral codes, many justify their actions as they do not consider it a serious enough offence to cause concern (Bain, 2015). Other students feel the subject is not of enough value to give it their full attention, so have few qualms about copying other people's work (Simmonds, 2018).

Cheating is not limited to those who feel they are unable to complete assignments; many high achievers also feel the pressure from their peers, and as they see the benchmark rising, some succumb to temptation and employ unscrupulous methods to stay abreast of their fellow classmates (Simmonds, 2018). The fact that classmates cheat is also a form of bonding; if one is happy enough to cheat, others feel much more comfortable doing so as they are all in the same situation together - a part of the gang (Simmonds, 2018).

\section{Strategies To Discourage the Use of Essay Mills and Support Students}

Universities must collaborate to combat essay mills and preserve the integrity of their institutions (Husbands, 2019). Leaving students open to abuse from these unethical, unprincipled 'businesses' is not an option, and to preserve the integrity, validity, the value of academic work, and the university degree, there has to be a concerted effort to better inform students of the pitfalls of employing essay mills (Husbands 2019). Staff training has also been suggested as a method to identify and discourage contract cheating; however, this primarily focuses on training the staff to find the contract cheats rather than support students before the act. While educating students on similarity software checking technology is certainly one way of discouraging would-be cheats, there is currently no software available to detect all cheats.

By using social marketing sites to advertise their services, essay mills might be seen to (for now, at least) have the upper hand (QAA, 2020). While the contract cheating industry ploughs new and improved technological furrows and enticing students into their folds of cheats, universities are, by and large, playing catch up (Crockett, 2020). That could soon change, as the UK's Northampton University has gone so far as to employ a stylometrist (Crockett, 2020). Stylometry is a system of detecting the variety of styles between a number of works from the same student (Crockett, 2020). Crockett's current job is to investigate contract cheating and 
teach teachers how to catch essay mill users - again, the focus being on catching the cheat after rather than looking into ways of preventing cheating from happening in the first place. What Crockett seems to have failed to grasp here, of course, is that one student could decide to use the same contract cheat to do their whole degree course.

Building a relationship based on personal and group trust, assigning responsibility, being inclusive and tolerant, and finally, being consistent are all aspects of helping students realise their duty to themselves, their peers and their universities' reputations (Cox, n.d.). While this may seem obvious, even the obvious needs reiterating regularly to keep teachers and students freshly aware of their obligations. The introduction of an honour code system could also help to decrease cheating (Bing et al., 2012).

There has also been backing for more research into defeating contract cheats from the UK Government. As well as former Education Minister, Joe Johnson's, plea to outlaw essay mills (Elmes, 2017), England's University Minister, Michele Donlan, Scotland's Minister for Further Education, Higher Education and Science, Richard Lochhead, and Wales' Minister for Education, Kirsty Williams, have all gone on record to voice their concerns on the scourge of essay mills and contract cheating (QAA, 2020). All ministers voiced concern at the active targeting of weaker and worried students during the COVID-19 pandemic (QAA, 2020) and as the UK has branch campuses in the UAE, this is a concern here too. With more training and a better knowledge of the students' work, technology and teachers together might be able to combat the problem, though to what extent remains to be seen.

Many students embark on their university studies without fully realising the steep learning curve in both the type of academic output or the expected quality of work from secondary to tertiary education (Nesi \& Gardner, 2012). That they fall behind with work, fail to understand the level of commitment necessary, and do not fully understand the ethical and moral standpoints have been well documented (Clarke \& Lancaster, 2006). Perhaps providing more support during their foundation or first year could be the answer. Employing more formative assessments; where teachers have a firmer grasp of, and a deeper day-to-day involvement in the students' work, could also provide a more robust way of ensuring academic integrity (Harrison, 2020; Lang, 2013). Although formative assessment does mean a heavier workload (or fewer students per class) and a more hands on teaching/capability building approach, it could well lead to a more involved learning process (Lang, 2013). This could increase the bond between tutor and learner, thereby creating a healthier and more trusting partnership that would encourage student honesty (Cox, n.d.). It could also mean that the teacher becomes more aware of all students' capabilities and is better equipped to recognise that which is original student work and that which is not.

\section{Findings And Discussion}

There is little doubt that the use of essay mills is on the rise, and much has been written on the effect it could have on the reputations and validity of university degrees (McCabe et al., 2001). To address this we must find ways to educate students on the value of honesty and integrity, focussing on their university's future standing and by association, the validity of their degree certificate. A greater focus has to be on prevention rather than cure, which could be achieved 
with more practical support for the student. This study aimed to explore the reasons behind students cheating, specifically with the use of essay mills in tertiary education in the UAE. The possible methods to stem or eliminate the use of contract cheat sites explored the following; the challenges second-language English speakers face in an English language medium degree, the students' perception of what cheating is, the reasons behind the use of essay mills, and the possible methods of discouraging of using such a means to complete a university degree.

The literature reviewed demonstrates a direct link between a lack of knowledge, poor time management skills, insufficient support, and mounting pressure for good grades and cheating. There is also evidence that as more direct plagiarism cases are discovered through similarity checking software, students will be more inclined to succumb to an offer of 'plagiarism-free' third-party assignments to pass a unit, course or degree they might otherwise fail. This research highlights the need for universities to offer better support and to have a closer academic relationship with students if essay mills and contract cheats are to be put out of business. However, due to human nature the likelihood of total eradication is rather slim.

\section{Summary, Reflection on Research and Further Research Requirements}

There is overwhelming evidence that academic inadequacy, a lack of language skills, the disillusionment with university degrees, and the realisation that a degree is not the panacea to future work prospects, drives people to essay mills (Lee, 2019). Studies also revealed that many students see a university degree as a commodity (Walker \& Townley, 2012) rather than something they take as a viable learning experience with them into the areas they might want to work. Therefore, as well as the benefits of a true life learning experience, there should also be the promise of a realistic job opportunity within that realm of the degree subject, which could discourage students from wandering into the realm of contract cheating. There is certainly evidence to show students with (more often than not running into multiple tens of thousands of dollars) degree debt hanging over them, or the guilt of a parental financial outlay for their studies are more likely to succumb to buying assignments (Kim, 2020). After all, a few dollars on top of what they have already paid is of little significance when a degree certificate appears to be the pot of gold at the end of the rainbow. There is also the point that many contract cheats are in their second or final year before they realise they are struggling to cope, and research suggests this is when they are most tempted into using an essay mill (Newton, 2018). After so much has already been invested, many see failing and losing the degree as motivation enough to type the words 'essay mill' into the Google search bar, hit enter, and choose from any one of the plethora of services they find.

There has been a rise in both awareness of essay mills and think-tanks on how to deal with the problem in countries with more on-shore campuses such as the United Kingdom. The QAA has issued guidelines that include: student support, authentic assignments, the blocking of essay mill websites through IT, awareness of posters and flyers circulating the university campuses to combat the use of essay mills (QAA, 2017). There has been no such research conducted in the UAE to discover the magnitude of the problem, and with so many second language English speakers in a satellite or branch campus off-shore context, this leaves plenty of scope for a further and more in-depth study. 
The ubiquity and ease of connection to an invisible friend willing to provide all the answers has appeared in the shape of 'Mr. Google', and this has provided a platform for such easy access to essay mills that many students now have the means, as well as in many cases the need, to purchase their assignment rather than complete it with their own original work (Locke et al., 2017). Franklyn-Stokes and Newstead (1995) found that while some students reported that purchasing assignments would devalue the sense of achievement they obtained from completing assessments on merit, it did not provide evidence of students being discouraged from buying them for fear of being found out. As many students take their old school habits with them when they go to university, they often do not realise that breaching academic integrity policies are serious cases that can lead to dismissal from the university course (Selwyn, 2008). There is also a measure of belief that if one person does it, then it is acceptable for others to follow: the socalled herd mentality (Locke et al., 2017), some students going as far as measuring their cheating as being less than others, and therefore feel they are not quite so guilty (Moss et al., 2018)

\section{CONCLUSION AND SUGGESTION}

More has to be done to combat the increasing use of contract cheats and essay mills in the UAE. If the reputation as one of the world's leading places for education is to hold value, adequate support must be provided to learners in the final tiers of secondary school and/or at foundation stages and first-year student at university. A number of reasons for using essay mills have been revealed, and research herein indicates that the ease of use, a lack of morals or ethics, a change in how degrees are viewed as commodities rather than learning experiences, a lack of support, a lack of understanding, peer, financial and parental pressure, as well as poor time management and frighteningly, a lack of ability, are the main reasons students turn to essay mills to provide their assignments rather than hand in orginially composed work and assignments. A number of these reasons also point a finger at the standards and due diligence when assessing the quality of admission standards, which must be addressed if progress is to be made.

If the use of essay mill services is to be reduced by any significant margin, Governments must initiate legislation to outlaw the practice. That, however, would not necessarily put a stop to the trade; merely move it to another geographical location where laws are not in place or are easier to circumnavigate. Governments could also legislate against the buyer and user, by making it a criminal offence to use essay mills. However, the most practical solution is surely to educate students of the morals and ethics of academic integrity, provide them with an understanding of the loss of worth in their degrees should the practice continue, and give them adequate, practical academic support. Only then might this illicit trade be addressed and curtailed.

\section{CONFLICT OF INTEREST}

There are no conflicts of interest with this paper.

\section{FUNDING}

No funding was received to complete this research.

\section{REFERENCES}


Ali, J. K. M. (2019). Investigating students' failure in English requirement courses. Journal of Social Studies. 25(3), https://doi.org/10.20428/JSS.25.3.5

Alkaabi, S. A. R., Albion, P., \& Redmond, P. (2016). Blended learning in the United Arab Emirates: Development of an adaptability model. Asia Pacific Journal of Contemporary Education and Communication Technology, 2(1), 64-86.

Anitsal, Ismet, M. Meral Anitsal and Robert Elmore. (2009). Academic dishonesty and intention to cheat: A model on active versus passive academic dishonesty as Perceived by Business Students. $\begin{array}{lllll}\text { Academy of } & \text { Entrepreneurship } & \text { Journal }\end{array}$ https://doi.org/10.1016/00221031(86)90045-4

Azjen, I., \& Madden, T. (1986). Prediction of goal-directed behavior: Attitudes, intentions, and perceived behavioral control. Journal of Experimental Social Psychology. 22(5), 453-474. https://doi.org/10.1016/0022-1031(86)90045-4

Bain, L. Z. (2015). How students use technology to cheat and what faculty can do about it. Information Systems Education Journal. 13(5) 92-99.

Bamford, J., \& Sergiou, K. (2005). International students and plagiarism: an analysis of the reasons for plagiarism among international foundation students. Investigationsișin in university teaching and learning 2(2), 17-22.

Barnard, R., \& McLellan, J., eds. (2013). Codeswitching in university English-medium classes: Asian perspectives. Multilingual Matters

Bennett, R. (2005). Factors associated with student plagiarism in a post. University, Assessment \& Evaluation in Higher Education, 30(2), 137-162. https://doi.org/10.1080/0260293042000264244

Bing, M., Kristl, D., Vittel, S., Ammeter, A., Garner, B., \& Novicevic, M. (2012). An experimental investigation of an interactive model of academic cheating among business school students. Academy of Management Learning \& Education, 11(1), 28-48. https://doi.org/10.5465/amle.2010.0057

Carnegie Council on Policy Studies in Higher Education. (1979). Fair practices in higher education: Rights and responsibilities of students and their colleges in a period of intensified competition for enrollments. Jossey-Bass.

Carpenter, D., Harding, T., Finelli, C., Montgomery, S, \& Passow. H. (2006). Engineering student's perceptions of and attitudes towards cheating. Journal of Engineering Education 95(3),181-194.

Chapman, K. \& Lupton, R. (2004). Academic dishonesty in a global educational market: A comparison of Hong Kong and American university business students. The International Journal of Educational Management 18(7),425-435. https://doi.org/10.1108/09513540410563130

Clarke, R., \& Lancaster, T. (2006). Eliminating the successor to plagiarism? Identifying the usage of contract cheating sites. In proceedings of 2 nd international plagiarism conference (pp. 1-13). Northumbria Learning Press.

Clarke, R., \& Lancaster, T. (2013). Proceedings of the 18th ACM conference on innovation and technology in computer science education - ITiCSE '13 Commercial aspects of contract cheating. https://doi.org/10.1145/2462476.2462497

Comas-Forgas, R., \& Sureda-Negre, J. (2010). Academic plagiarism: Explanatory factors from students' perspective. Journal of Academic Ethics 8(3). https://doi.org/10.1007/s10805-010-9121-0

Coren, A. (2012) The theory of planned behaviour: Will faculty confront students who cheat? Journal of Academic Ethics 10, 171-184. https://doi.org/10.1007/s10805-012-9162-7

Cox, J. (n.d.). How to build trust with your students. Hey Teach. Western Governors University. https://www.wgu.edu/heyteach/article/how-build-trust-students1808.html

Crane, L. (n.d.) Plagiarism, cheating, and getting ahead. TESOL International Association. https://www.tesol.org/read-and-publish/journals/other-serial-publications/compleat-

links/compleat-links-volume-4-issue-1-(march-2007)/plagiarism-cheating-and-getting-ahead

Cressey, D. R. (1973). Other people's money. Montclair: Patterson Smith. 
Crockett, R. (2020). Innovative steps in tacking contract cheating at the University of Northampton. QAA. https://www.qaa.ac.uk/news-events/blog/innovative-steps-in-tackling-contract-cheatingat-the-university-of-northampton

Crossman, G. (2019). Combatting essay mills and academic misconduct. Quality Assurance Agency. https://www.qaa.ac.uk/news-events/blog/combatting-essay-mills-and-academic-misconduct\#

Davies, L. J. P., \& Howard, R. M. (2016). Plagiarism and the internet: Fears, facts, and pedagogies. In T. Bretag (Ed.). Handbook of academic integrity (pp. 591-606). Springer Nature: Springer Science Business Media. https://doi.org/10.1007/978-981-287-098-8_16

Davis, S. F., Grover, C. A., Becker, A. H., and McGregor, L. N. (1992). Academic dishonesty: prevalence, determinants, techniques, and punishments. Teaching of Psychology. 19, 16-20. https://doi.org/10.1207/s15328023top 1901_3

Department of Education. (2019). Government pledge to 'beat the cheats' at university. https://www.gov.uk/government/news/government-pledge-to-beat-the-cheats-at-university

Eisenberg, J. (2004). To cheat or not to cheat: effects of moral perspective and situational variables on students' attitudes, Journal of Moral Education, 33(2), 163-178, https://doi.org/10.1080/0305724042000215276

Elmes, J. (2017) Minister calls for tougher penalties to combat essay mills. Times Higher Education. Times Newspapers. https://www.timeshighereducation.com/news/minister-calls-tougherpenalties-combat-essay-mills

Franklyn-Stokes, A., \& Newstead, S. E. (1995). Undergraduate cheating: Who does what and why? Studies in Higher Education, 20(2), 159-172. https://doi.org/10.1080/03075079512331381673

Furedi, F. (2003). Shortcut to success. Times Higher Education Supplement. p. 16.

Gassin, J. (1982) The learning difficulties of the foreign student and what we can do about them. Herdsa News, 4 (3), 13-16

Harrison, D. (2020). Online education and authentic assessment: How do we keep our students from cheating on online Inside Higher Ed. https://www.insidehighered.com/advice/2020/04/29/how-discourage-student-cheating-onlineexams-opinion

Husbands, C. (2019). Essay mills prey on vulnerable students - let's stamp them out. The Guardian. Guardian Newspapers. https://www.theguardian.com/education/2019/mar/20/essay-mills-preyon-vulnerable-students-lets-stamp-them-out

Jurdi, R., Hage, H. S., and Chow, H. P. H. (2012). What behaviours do students consider academically dishonest? Findings from a survey of Canadian undergraduate students. Society of Psychological Education. 15, 1-23. https://doi.org/10.1007/s11218-011-9166-y

Kaktiņš, L. (2018) Contract cheating advertisements: what they tell us about international students' attitudes to academic integrity, ethics and education, 13(2), 268-284. https://doi.org/10.1080/17449642.2017.1412178

Kelly, R. (2017). Survey: Blended learning on the rise. Campus Technology. https://campustechnology.com/articles/2017/09/20/survey-blended-learning-on-the-rise.aspx

Kim, J. L. (2020). Asian parents who say 'I criticise because I care'. Psychology Today. https://www.psychologytoday.com/us/blog/asian-self-help/202005/asian-parents-who-say-icriticize-because-i-care

Krou, J. (2015) Rationalizing the decision to cheat: an empirical analysis to determine whether social rational orientation can predict academic dishonesty [Master of Arts thesis, Texas State University]. https://digital.library.txstate.edu/bitstream/handle/10877/6820/KROU-THESIS2015.pdf?isAllowed $=\mathrm{y} \&$ sequence $=1$

Lang, J. M. (2013). Cheating lessons, part 2. The Chronicle of Higher Education. http://chronicle.com/article/CheatingLessons-Part-2/140113/ 
Lee, C. (2019). Straight talk from an essay mill insider: Part 1 of 2. Turnitin.com retrieved from https://www.turnitin.com/blog/straight-talk-from-an-essay-mill-insider-part-1

Lillis, T. (2001). Student writing: Access, regulation, desire. Routledge.

Locke1, K. D., Church, A. T., Mastor, K. A., Curtis, J. A., Sadler, P., McDonald, K., Vargas-Flores, J. d. J., Ibáñez-Reyes, J., Morio, H., Reyes, J. A. S., Cabrera, H. F., Arias, R. M., Rincon, B. C., Arias, N. C. A., Muñoz, A., \& Ortiz, F. A. (2017). Cross-Situational self-consistency in nine cultures: The importance of separating influences of social norms and distinctive dispositions. Personality and Social Psychology Bulletin, 43(7), 1033-1049. https://doi.org/0.1177/0146167217704192

Ma, H. J., Wan, G., \& Lu, E. Y. (2008). Digital cheating and plagiarism in schools. Theory into Practice, 47(3), 197-203. https://doi.org/10.1080/00405840802153809

McCabe, D. L. (2004) Student cheating: crisis or opportunity? [Conference presentation]. Center for Academic Integrity Conference, Kansas State University

McCabe, D.L., Trevino, L.K., \& Butterfield, K.D. (2001). Cheating in academic institutions: A decade of research. Ethics and Behavior, 11(3), 219-232. https://doi.org/10.1207/S15327019EB1103_2

Mellar, H., Peytcheva-Forsythe, R., Kocdar, S., Karadeniz, A., \& Yukova, B. (2018). Addressing cheating in e-assessment using student authentication and authorship checking systems: teachers' perspectives. International Journal for Educational Integrity, 14(1), 1-21. https://doi.org/10.1007/s40979-018-0025-X

Millar, A., Shoptaugh, C. \& Wooldridge, J. (2011). Reasons not to cheat, academic-integrity responsibility, and frequency of cheating. The Journal of Experimental Education. 79(2), 169184. https://doi.org/10.1080/00220970903567830

Moss, S. A., White, B., and Lee, J. (2018). Systematic review into the psychological causes and correlates of plagiarism. Ethics Behavior. 28, 261-283. https://doi.org /10.1080/ 10508422.2017.1341837

Newton P. N. (2018). How common is commercial contract cheating in higher education and is it increasing? A systematic review. Front. Education. 3(67), 1-18. https://doi.org/10.3389/feduc.201800067

Nesi, H., \& Gardner, S. (2012). Genres across the disciplines: Students writing in higher education. Cambridge University Press.

Neumann, R. (1985). English Language Problems and University Students from a Non-English Speaking Background. Higher Education Research \& Development, 4(2), 193202. https://doi.org/10.1080/0729436850040207

Quality Assurance Agency. (2017). Contracting to cheat in higher education: How to address contract cheating, the use of third-party services and essay mills. https://www.qaa.ac.uk/docs/qaa/qualitycode/contracting-to-cheat-in-higher-education.pdf

Quality Assurance Agency. (2020). QAA publishes new guidance to help tackle the use of essay mills. https://www.qaa.ac.uk/news-events/news/qaa-publishes-new-guidance-to-help-tackle-the-use-ofessay-mills

Sarita, R. D. (2015). Academic cheating among students: Pressure of parents and teachers. International Journal of Applied Research. 1(10), 793-797.

Sawir, E. (2005). Language difficulties of international students in Australia: The effects of prior learning experience. International Education Journal, 2005, 6(5), 567-580. Shannon Research Press.

Selwyn, N. (2008). 'Not necessarily a bad thing': a study of online plagiarism amongst undergraduate students. Assess. Evaluation of Higher Education. 33, 465-479. https://doi.org/10.1080/02602930701563104

Simmonds, A. (2018). Why students cheat - and what to do about it. Edutopia. https://www.edutopia.org/article/why-students-cheat-and-what-do-about-it 
Singh, S., \& Remenyi, D. (2016). Plagiarism and ghostwriting: The rise in academic misconduct. South African Journal of Science, 112(5/6). https://doi.org/10.17159/sajs.2016/20150300

Smith, K. J., Davy, J. A., \& Easterling, D. (2004) An Examination of cheating and its antecedents among marketing and management majors, The Journal of Business Ethics. 50(1), 66.

Taylor, L., Pogrebin, M., \& Dodge, M. (2002). Advanced placement advanced pressures: academic dishonesty among elite high school students. Educational Studies, 33(5), 403-421.

Tertiary Education Quality Standards and Assurance. (2020). Toolkit to support quality assurance agencies to address academic integrity and contract cheating. Tertiary Education Quality Standards and Assurance https://www.teqsa.gov.au/sites/default/files/inqaahe-teqsa-qbbgacademic-integrity-toolkit-v1-0.pdf?v=1594958272

Turner, C., Opulencia, C., \& Woodyatt, A. (2018). Unscrupulous' essay mill companies are using social media to tempt students into cheating. The Telegraph. https://www.telegraph.co.uk/education/2018/10/27/unscrupulous-essay-mill-companies-usingsocial-media-tempt-students/United Arab Emirates Higher Education. (n.d.) https://education.stateuniversity.com/pages/1610/United-Arab-Emirates-Higher-Education.

United Arab Emirates Higher Education. (n.d.) Education Encyclopedia. StateUniversity.com https://education.stateuniversity.com/pages/1610/United-Arab-Emirates-HIGHER-EDUCATION.html University of Toronto, (n.d.). Why is academic integrity and honesty important? https://secure.tlc.ontariotechu.ca/academic_integrity/module1/Module13.html

Uzun, A. M., \& Kilis, S. (2019). Investigating antecedents of plagiarism using extended theory of planned

behavior. Computers \& Education. https://doi.org/10.1016/j.compedu.2019.103700

Walker, M., \& Townley, C. (2012). Contract cheating: a new challenge for academic honesty? Journal of

Academic Ethics, 10(1), 27-44. https://org.doi/10.1007/s10805-012-9150-y

Weimer, M. (2009). Why students don't ask for help, and what you can do about it. Faculty Focus. https://www.facultyfocus.com/uncategorized/why-students-dont-ask-for-help-and-what-you-cando-about-it/

Wolverton, B. (2016). The new cheating economy. Chronicle of Higher Education 63(1), A40-A45. http://web.a.ebscohost.com/ehost/detail/detail?vid=11\&sid=91248baf-6e89-4755-bf8c9decd24b2b08\%40sessionmgr4006\&hid $=42$ 06\&bdata=JnNpdGU9ZWhvc3QtbGl2ZQ\%3d\%3d\#AN=117829263\&db=aph

Zayed, N. M. (2015). Do you use English in Dubai as a foreign or second language? International Journal

on Studies in English Language and Literature. 3(1), 54-66 